\title{
The Development, Design, and Implementation of a Library Assessment Framework
}

Holt Zaugg

Brigham Young University, holt_zaugg@byu.edu

Follow this and additional works at: https://scholarsarchive.byu.edu/facpub

Part of the Library and Information Science Commons

\section{Original Publication Citation}

Zaugg, H. (2020). The development, design, and implementation of a library assessment framework, Journal of Library Administration, 60(8), 909-924.

\section{BYU ScholarsArchive Citation}

Zaugg, Holt, "The Development, Design, and Implementation of a Library Assessment Framework" (2020). Faculty Publications. 4424.

https://scholarsarchive.byu.edu/facpub/4424 


\section{The Development, Design, and Implementation of a Library Assessment Framework}

\section{Holt Zaugg}

To cite this article: Holt Zaugg (2020) The Development, Design, and Implementation of a Library Assessment Framework, Journal of Library Administration, 60:8, 909-924, DOI: 10.1080/01930826.2020.1820277

To link to this article: https://doi.org/10.1080/01930826.2020.1820277

曲 Published online: 22 Sep 2020.

Submit your article to this journal $₫$

Llll Article views: 77

Q View related articles ๘

View Crossmark data $\nearrow$ 


\title{
The Development, Design, and Implementation of a Library Assessment Framework
}

\author{
Holt Zaugg \\ Assessment Librarian, BYU Library, Provo, UT, USA
}

\begin{abstract}
Common in the language and actions of libraries is the desire to develop and foster a culture of assessment and evaluation. However, most employees in a library have had limited or no experience in designing, conducting, analyzing, and disseminating library assessments. Those who do have experience tend to draw from their personal discipline background that emphasizes one type of method over another. Typically, when these assessments happen, the efforts are one-off or siloed assessments. To create and foster a culture of assessment a framework is needed to guide and support all library assessments. A library assessment framework helps library employees see where their assessment fits into the overall library strategic planning and improvement processes. It informs them regarding what assessment services are available for supporting their efforts. In short, a library assessment framework helps all library employees contribute to the culture of assessment. This article describes the tools used to develop a librarywide assessment framework, the components of an assessment framework, and how the assessments tie into library and university aims and goals. Example templates are provided in Appendices.
\end{abstract}

\section{KEYWORDS}

Assessment; evaluation;

strategic planning; assessment culture; evaluation culture

\section{Introduction}

In an age of data-based decision-making, more and more libraries are designating personnel specifically to conduct assessments. Libraries have long collected data related to key library functions, such as total resources, resources checked out, and number of users entering the library. However, in this era, data support and inform decision-making, strategic planning, and determination of library value. Assessments need to examine more than the easy-to-count data; they must also evaluate library patrons' experience as they interact with library services, spaces, and resources (Tatarka et al., 2010). Librarians need to be aware of how to use assessments effectively to assist in the discharge of their duties and future planning.

\section{Literature review}

Librarians tasked with conducting assessments often cater the assessment to the specific needs of the library, ranging from simple, one-time assessments (e.g., employees

CONTACT Holt Zaugg holt_zaugg@byu.edu $@$ Assessment Librarian, BYU Library, P.O. Box 26800, Provo, UT 846026800 , USA. 
selecting fabric for break-room furniture) to complicated, repeating assessments (e.g., determining where students study prior to and following renovations). Avery (2015) indicates that assessment librarians help library personnel understand how to build and improve on current practices, evaluate their progress in meeting library goals, and better recognize how individual work contributes to overall improved service and value. This expansion of data collection to inform decisions and planning often uses a variety of sources. In some instances, libraries join national assessment efforts such as Ithaka, LibQUAL $^{+}{ }^{\circledR}$, or MISO to assess their impact and influence within their own institution and to compare themselves with other institutions. In other instances, library assessment efforts help librarians adopt assessment programs, adapt current assessment programs, or use elements from existing evaluation programs to fit their assessment needs (Cox et al., 2019). The intent is to examine how the library is supporting student learning, connecting to the aims and goals of the library and the university, and describing value (ACRL, 2010; Hockenberry \& Little, 2013; Lindauer, 1998; Matthews, 2007). Each library develops assessment plans that meet its specific needs with the resources it has available.

When library resources are limited, university faculty members who teach courses related to qualitative or quantitative methods or concepts may be asked to participate. In these instances, faculty instructors use the library assessment as a course focal point or project. In addition to learning new skills, students are able to apply the principles they have learned in an assessment that gives them real-world experience and provides key data for librarians (Zaugg \& Child, 2016).

A review of some of library assessment plans from a variety of institutions indicates that they vary in detail, the outline of what will be assessed, who will conduct the assessment, when the assessment will occur, and what assessment methods will be used. Other assessment plans are simpler, in that they only contain some of these assessment components. Assessment plans that will be conducted in the future must have built-in flexibility to accommodate unexpected changes, such when library services or spaces are altered.

In some instances, librarians charged with conducting an assessment work with other library employees to collect and analyze data. These efforts foster a culture of assessment, where employees throughout the library participate in and value assessment (Lakos, 2007). Applegate (2009) advocates for an organizational assessment plan to ensure that assessments, which benefit the library and its users, encompass the entire library to prevent duplication and bother. She further recommends that libraries use a bottom-up approach in which they identify data sources and track important data over time to determine changes in the library and its patrons.

Baggett et al. (2018) further advocate for implementing library assessments that provide insights into an organization's priorities and changes in over time. Assessments like these determine what has been assessed and when to examine the impact of assessments on changes within the library. Dunya and De Groote (2017) indicate that few libraries document how assessment plans were initially created and how they evolved over time. This process is important because it helps to show progression and to provide reasons why assessments were and are conducted to inform future planning. Regardless of the size of the library, an individual or even a committee tasked with 
conducting assessments would not have the ability to assess all library services, resources, and spaces. While librarians are good at collecting data, especially as it relates to their library duties, many are not familiar with how to conduct assessments and may not see the "big picture" of how an assessment fits into overall library assessment.

This article describes the process of developing and implementing a library assessment framework at the Harold B. Lee Library (BYU Library) at Brigham Young University (BYU). Librarians, who do and do not have training in conducting assessments can use this framework as a reference in developing an assessment framework for their academic library. An assessment framework indicates roles and responsibilities in assessments and provides a connection to academic library assessments. In doing so, the framework guides assessment plans to ensure that all academic library services, spaces, and resources are assessed fairly and thoroughly.

\section{Description of BYU Library}

BYU Library occupies a central location on the BYU campus. It serves approximately 33,000 faculty, staff, and students across 13 colleges. It hosts approximately six million items across six floors in an area of about 665,000 square feet $(60,850$ square meters). During prime semesters (fall and winter), it serves upwards of 15,000 patrons each day. Assessments within the library are conducted and coordinated by the library's Assessment Office (AO), which includes a full-time assessment librarian, a full-time process-improvement specialist, a full-time user-experience specialist, and two half-time student employees.

\section{Development of an assessment framework}

A library-wide assessment framework provides a road map for how assessments will occur in the library. What follows is the process the BYU Library AO used to develop an assessment framework for the library. These actions did not happen sequentially nor do they necessarily need to occur in this order, but each action is presented in an order in which it is felt that they would be most effective. We begin with some background work that needs to occur to help inform the assessment framework.

Prior to developing an assessment framework, library personnel need to know where they are; they must assess the current status of assessment within the library. This process includes identifying what assessments have been done or are underway. It examines what data is currently being collected or may be collected in the future and how that data are or can be used. Different types of data allow those conducting assessments to see both the big picture and specific areas of the library. Some of these assessments may include a library impact map, a data inventory, a review of completed assessments, and a strategic planning map. Each of these assessments is briefly discussed below, including a description of how BYU implemented it. 


\section{Library impact map}

The library impact map (LIM) provides an overall view of where data are collected and how the data impact the university, and it also allows librarians to hone in on an interaction between a single university focus and a library service (Applegate, 2009; Hockenberry \& Little, 2013). It is not expected that any one library service will provide data about the library's value for all areas of university focus; however, all areas of university focus should be covered by some library service. The LIM also indicates areas of university focus that may be over- or under-assessed.

A LIM places areas of university focus as the row headers and library services as the column headers (Oakleaf, 2012). Both lists may be as broad or narrow as desired. For example, the areas of university focus may only include those areas that address one of the university's goals or aims, or it may seek to examine all areas of focus for all of the university's goals and aims. Similarly, the library may narrow the focus to a single department or division, or it may include all key library services. At the intersection between university areas of focus and library services, library employees indicate the degree to which there is a relationship impact, ranging from no impact to a full impact, which is then communicated to stakeholders. The LIM identifies if there are data supporting these assertions of the library's value.

The BYU Library conducted a LIM several years ago to indicate areas where data are collected (see Appendix A). The results allowed assessment personnel to examine easyto-collect data that was subsequently displayed on live dashboards. It also identified the areas where assessment could occur. The LIM should be periodically repeated to determine what, if any, changes have occurred.

\section{Data inventory}

Libraries collect and use a lot of data. A data inventory is a process used to identify the types of data each library employee creates, uses, or would find beneficial to have. It may be conducted in a number of ways, but it should involve all library employees. For each library employee, the data inventory catalogs what type of data is being collected, why it is collected, where it is stored, and how it is used.

Assessment office employees at the BYU Library created a data inventory by conducting a survey and follow-up interview with all library employees. The result is an inventory of collected data (Zaugg et al., 2017). Used as a companion with the LIM, a data inventory identifies data that can be used to indicate the library's impact on learning and research activities in the university or to provide information for a specific area of university focus. These data can be used to assess areas of university focus that have been under assessed. The data inventory also helps to identify data collection that is no longer useful, allowing the library to save resources (Applegate, 2009; Dunya \& De Groote, 2017; Lindauer, 1998).

\section{Completed assessments}

Any completed assessments of library spaces, services, or resources should be examined collectively to determine what has been assessed and by whom. Using a grid similar to 
the LIM, each assessment is identified as assessing a service, a space, or a resource and becomes a row header. Library divisions, departments, or units become the column headers. A column for library-wide assessments should also be included. The cross-section indicates what has been assessed in the library and where in the library the assessment occurred. Doing so helps to determine if some areas were over assessed and other areas were under assessed. Completed assessments may be categorized in several ways, but the categorization should communicate what has been assessed and has yet to be assessed.

At the BYU Library some assessments involved more than one division, department, or unit. The result is that there may be multiple intersections between assessments and library divisions, departments, or units. In the BYU Library there was 17 intersections involving spaces. Some library departments and units (digital initiatives, cataloging and metadata, and material acquisition) did not have any completed assessments. In these instances, assessment personnel can check if data are being collected or assessments are being conducted but not reported. This information helps library personnel identify where assessments may need to occur.

There may also be reasons for overassessments. For example, the BYU Library is currently engaged in a 10-year renovation plan to modernize the building and to improve its spaces. The abundance of library-wide and facility assessments explain the data collection efforts to inform decisions.

\section{Strategic planning}

Strategic planning takes a look at what is currently happening in the library along with trends and patterns from the past. These two views help library employees look forward to anticipate the needs of students and to plan for needed changes. The strategic plan is typically completed by library leadership who have a connection to the future projects. Strategic planning is often undertaken at a library leadership retreat.

A strategic planning review is also done on a grid, but unlike the LIM and the completed assessments, it examines future projects. The column headers remain the library divisions, departments, and units, but the row headers are replaced with future projects the library wishes to undertake. The intersection between the two indicates which the division, department, or unit currently collects or may collect the data that inform decisions. This intersection may also be used to indicate who has the primary responsibility for collecting data.

These four preliminary tasks serve as metadata points that examine the past (completed assessments), the present (LIM and data inventory), and the future (strategic planning). They serve as a starting point and should not be considered a one-and-done effort. These tasks should be repeated and updated periodically to allow comparison with the initial baseline. Examining the repeated longitudinal nature of these assessments allows library personnel to measure the evolution of a culture of assessment within the library (Baggett et al., 2018; Lakos, 2007). 


\section{Components of an assessment framework}

Using the data from these preliminary reviews, the assessment framework provides an outline for assessment planning within the library. The framework allows librarians to determine where any assessment, including their own, fits within an overall assessment framework. It also helps to define which services the library's AO will provide to assist in assessment. For example, if those in charge of help desks want to assess their service, they may ask the AO for assistance in designing the assessment, but collect and analyzed the data on their own. Additionally, the assessment framework helps connect each library assessment to library and university aims and goals. It also defines assessment tasks, the areas or objectives of assessment within the library, roles and responsibilities of assessment, and how assessments are disseminated and used. Each of these areas is briefly discussed and examples provided from the BYU Library.

\section{Aims and goals}

Each university has a mission statement, aims, goal statements, or a combination of all three, outlining the university's hopes for its students' learning and development. The library goals and objectives have a dual focus. First, they map onto the university statements in a way that indicates how they contribute to fulfilling the university mission, aim, and goal statements. Second, they also map onto the goal statements of regional or national organizations. Comparing its own goals statements to those of other organizations can help the library maintain and improve its standards. In both instances, the library is able to define its value within the university and the larger university community as it meets the learning needs of its patrons.

The BYU Library has five goal statements:

1. Inspiring Learning: Recognizing and acting upon opportunities that allow students to have the best experiential learning in their scholarship or as library employees.

2. Access: Improving discoverability of and access to resources-especially those unique to BYU-to support scholarship and to maximize our investment in acquiring and preserving this material.

3. Spaces: Providing spaces that facilitate collaboration, experimentation, creation, and discovery.

4. Collaboration: Fostering deep collaboration that produces new knowledge (research) and facilitates learning.

5. Personnel: Developing our people so they can lead, facilitate, and respond to the changes that we need to address (Strategic Directions, 2019).

An example of the BYU Library meeting some of these goals statements is the recent addition of a Creativity, Innovation, and Design (CID) space where faculty from across campus can teach interdisciplinary classes focused on creativity, innovation, and design. Each class has a librarian embedded in the course instruction and typically focuses on a course project. Assessments of this space link to goal statements 2-4 as they examine the role of the embedded librarian in assisting students in discovering resources. They 


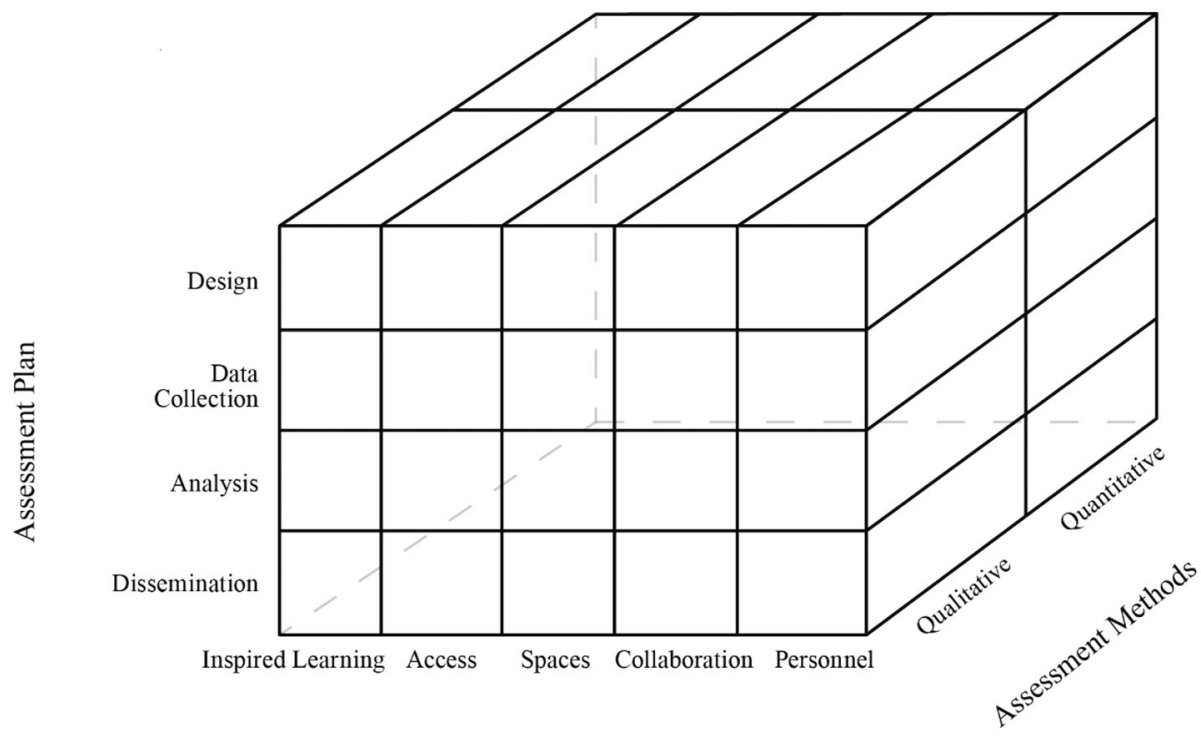

Library Directions

Figure 1. Model of assessment framework within the BYU Library.

review how the space fosters interaction between faculty and librarians and among students and show where improvements can be made.

Once the connection to library goals is made, the framework provides a view of options for assessing library goals. This includes understanding potential assessment methods, library objectives, and the components of an assessment plan, as illustrated in Figure 1.

\section{Assessment methods}

It is beyond the scope of this article to discuss all of the assessment methods a library might use, but they may include quantitative methods, qualitative methods, or a combination of the two. The intent is that library personnel would have a repertoire of assessment methods that best suits the specific assessment. Using several assessment methods allows librarians to triangulate findings and gain a better understanding of the results. The inclination to use only one assessment tool or overuse an assessment tool should be avoided.

For example, while a survey may help to determine how students viewed library instruction, it may also be helpful to have a colleague provide observations of library instruction, noting types of questions asked, movement of the instructor, and other factors deemed important for the instruction. The instructor could also reflect on how well he or she felt the instruction went. These three data sources would enable the instructor to triangulate his or her perspectives with those of an observer and those of the students to see how well they align and what changes might improve instruction.

Regardless of the assessment, assessment tools that fit the assessment should be used and should consider factors such as time available, cost, depth of the assessment, and analysis of the data. 


\section{Library directions}

The library directions define the objectives and purpose of the library. They are a driving force behind the decisions made to maintain or improve library services and directly link the library and the university goal statements. They also serve as a frame of reference for determining where assessments should occur. Below is a brief description of BYU Library's directions with examples.

\section{Inspiring learning}

BYU emphasizes inspired learning. This effort asks faculty to go beyond providing information by creating educational experiences that allow students to gain practical experience along with theoretical learning in ways that inspire them to bless the lives of others. An example includes library employees mentoring students. In some circumstances, students are drawn into library assessments as part of their research methods courses. This participation in library assessments enables them to collect and analyze data. It also provides a real-world experience to which they can apply their class learning. In another example, the CID space brings students from various disciplines and matches them with partners external to the university to create solutions for real-world problems. Librarians are integrated within the courses to help these students access library resources.

\section{Access}

There are two pathways to library access-via the library's website and in person. Effective website access includes having a website that is clear and easy to use. The BYU Library's IT division developed a website with a fluid design so it has the same look across multiple access devices (smartphone, tablet, computer). Assessments of the website upon its release established baseline use data while providing additional insights on how to improve the website. Six years later, a repeat assessment helped to define changing access and use patterns. Both assessments inform how the library's web development team responds to students' changing needs.

Effective in-person access includes library instruction, subject librarian consultations that help students learn how to access materials to assist them with their learning and research activities, and accessing other library resources. Assessments typically include how many classes or consultations occurred in a given time period (i.e., semester or year) and the number of participants. Assessment efforts also examine how using different instruction methods (i.e., flipped classroom) or preliminary online resources improves instruction. Assessments also help to determine the value of this instruction to those engaging in research. The BYU Library developed five online modules for use in library instruction. Prior to instruction students view a module that prepares them for class discussion. Assessment helped in the development of these modules and indicated their value once they were implemented. 


\section{Spaces}

One of Ranganathan's Five Laws of Library Science (1931) states that there is a book for every person. An extension of this for the physical library is that there is a space for every patron. Assessments examine spaces, including experimental or pilot spaces, to determine what types of spaces are or could be beneficial to students and faculty, with the goal of providing the spaces needed by students and faculty for specific learning or research activities. In the BYU Library some of the spaces developed after assessments include a family-friendly study room for parent students, new individual-study desks, and furniture students can move and adjust to meet their needs The circulation desk and a help desk were also combined into a single location to free up more study space for students. In each instance, assessments initially informed the final design of the space and, in most, follow-up assessments determined if the spaces were being used as intended and what value the space added to students.

\section{Collaboration}

Library personnel collaborate in several ways with other faculty and students. These collaborations help faculty and students find and use resources critical to their courses and research, many of which often result in publications or conference presentations. These collaborations are assessed through publishing metrics such as citations, views, and downloads. Creating spaces within the library where collaboration can occur assists students as they work in groups or connect with others outside of the library to expand their learning.

As the BYU Library moves forward with its long-term renovation plans, assessments help to inform how spaces are changed. For example, one assessment indicated that the vast majority of group study rooms were used by four or fewer students. Part of the renovations includes making smaller group study rooms so there are more study rooms that enables more students to use the study space and meet the needs of smaller groups.

\section{Personnel}

Assessments of personnel does not refer to the yearly review of library employees by their superiors. Rather, it refers to the ways personnel interact with each other and issues that affect personnel. As an example, the assessment office conducted a communication network analysis of library employees. It not only examined the library employees who interacted with one another using several communication methods (e.g., phone, e-mail, text message, in person), but it also considered the frequency and depth of the communications. This information helped library personnel understand who they communication with and how they communicated.

Another example is the creation and revision of process flow charts that indicate how tasks between library personnel are completed. It describes the way things are done so that library employees have a pathway and information of who to contact and when. Once completed the process flow charts are continually reevaluated to determine if there is a better or more efficient way of doing things. 


\section{Assessment plan}

The assessment plan is the working document that outlines current assessments. This plan serves two primary purposes. First, it ensures that current assessments are aligned with the library goal statements and, by default, the university aims and goals. Second, it specifies who will conduct the assessments and how data will be collected, analyzed, and disseminated. The assessment plan also includes ongoing journal of all assessment activities, which provides a record of past assessments and how they have been conducted. Should there be a change in assessment personnel, new employees can quickly get up to speed on the assessments.

The assessment plan is crafted toward the institution and the resources available for assessments. For example, in some libraries, one or two staff members may be responsible for all assessment efforts in the library, while in another a committee may conduct assessments. Typically, the assessment plan includes:

- Assessment title

- Location of files associated with the assessment

- Timing of assessment activities, including their relation to other on-going assessments

- Assessment members, including who is the principal investigator and the library department involved in the assessment

- Alignment with library objectives

- Status of assessment (pilot or full assessment, if an ethics review is needed)

- Research methods

- Special circumstances of the assessment

- Log of research activities

In the BYU Library, assessments are conducted and coordinated by the $\mathrm{AO}$, which is comprised of three full-time nonstudent employees and two part-time employees. The AO has four primary responsibilities or duties-design, data collection, analysis, and dissemination. Each is briefly discussed below.

\section{Design}

Design refers to all activities associated with the planning of an assessment, which may include choosing assessment methods, identifying ethical responsibilities, outlining the timing and location of assessment activities, selecting assessment tools, writing or reviewing institutional review board (IRB) proposals (or both), and ensuring compliance with university data collection policies. In design, the AO seeks to identify and plan the assessment to ensure that the collected data answers the questions to help in planning and decision-making. The data collection tools are also reviewed to ensure that the data collected can be analyzed in appropriate and meaningful ways. 


\section{Data collection}

Data collection refers to the tools identified in the design responsibility. Tools typically include quantitative, qualitative, or mixed-methods approaches. Data collection may be an ongoing process (e.g., gate counts), repeated assessments, or one-and-done initiatives. The data collection may involve a single staff member or a cadre of assessment personnel.

\section{Analysis}

Once data are collected, it is analyzed using prescribed qualitative or quantitative procedures. Analysis includes de-identifying sensitive responses to preserve the identity of respondents and maintain confidentiality. Where statistical significance is determined and reported, the analysis examines whether the statistically significant results also have a practical significance-are the significant changes worth the effort to achieve the significant gains?

\section{Dissemination}

Assessment results should be disseminated within the library and may be disseminated outside of the library. Internal dissemination efforts may include a weekly report to superiors, a monthly status report to all library employees, dashboards that summarize ongoing data collection, and/or a final report and presentation to library employees. At the BYU Library, final reports are typically posted on the AO's wiki page and may include presentations at library-wide town meetings. External dissemination efforts may include presentations at conferences, symposia, or workshops and peerreviewed articles.

If the $\mathrm{AO}$ is conducting the full assessment, they assume responsibility for all four $\mathrm{AO}$ duties in the assessment plan. If they are consulting with others conducting assessments, they work on the requested component. For example, when the Science Help Desk wanted to assess their service, the AO assisted in the design, including creating the survey, reviewing the IRB application, and providing an iPad for data collection. Science Help Desk personnel completed all other assessment tasks (data collection, data analysis, and dissemination).

In addition to these four responsibilities, an assessment plan should indicate whether the assessment should be repeated. In some instances, only one assessment may be needed. For example, if a library is getting new furniture for a break room, a survey to determine final fabric choices may be conducted. Once the assessment is completed, there is no need to repeat it. Some assessments need to be ongoing, such as collecting the counts of patrons and number of transactions each day. In these instances data is typically collected automatically and is periodically referenced (e.g., each quarter, semester, or year) for reports and to show patterns over time. The data collection is continuous, even as a report is written and released.

Other assessments should be repeated. There are two types of repeated assessmentsa verification assessment and a pattern change assessment. A verification assessment follows the initial assessment and determines if a necessary change was implemented as 
planned. In the BYU Library, a verification assessment was conducted after the addition of the Family Friendly Study Room (FFSR) and new independent study desks (ISD). The initial assessment for the FFSR determined how big the space should be, where it should be located, the amenities needed, and the policies governing its use. After a semester of FFSR promotion and use, the verification assessment indicated whether the space was the proper size and in the correct location; what, if any, additional amenities were needed; and the impact of the space on students with children.

The initial ISD assessment determined the features the new ISDs should have and assessed the ISD prototypes. When about half of the old ISDs had been replaced by the new ISDs, a verification assessment helped to determine key differences that impacted students using an ISD. With both the FFSR and the ISDs, the verification assessment verified that the changes indicated by the initial assessment were correct and necessary.

The pattern change assessment identifies changes in use patterns. After baseline data are collected, the assessment is repeated after a period of time to note which use patterns have changed and which have not. The BYU Library conducted a pattern change assessment to examine use patterns for the library's website across different access devices (smartphone, tablet, computer). Six years after the release of the new website and its initial assessment, the assessment was repeated to determine what, if any, changes there were in how students accessed the library's website.

\section{Future assessments}

Embedded within each assessment should also be a thoughtful schedule of future assessments. These future assessments include when to examine ongoing or repeated data collection efforts. While ongoing data are often examined at defined periods (e.g., each semester or year), it is also wise to examine long-term trends. If an assessment has been conducted over several years, examining its findings may show patterns of success, value, and areas that need improvement.

One such example at the BYU Library involved administering the LibQUAL ${ }^{+}$survey biennially for over a decade. Using the open-ended comments from each administration, the library examined six areas (staff, building, on-site resources, web-based resources, policies, and communication) to determine if the number of positive comments were increasing and the negative comments decreasing. The results showed improvement in several of the six areas but indicated other areas that needed work. While this future assessment looked back, it also helped the library know if changes made in the library were moving in a desired or undesired directions.

The importance of future assessments is to plan for a look back. Unlike research that is continually looking for some new discovery, assessment is often a repeated venture that indicates how services, resources, and spaces have changed or are changing. Knowledge about these changes enables the library to adapt and stay relevant in the lives of students. 


\section{Conclusion}

A library-wide assessment framework provides a road map for how assessments will occur in the library. The framework assists in describing the library's value as it connects to library and university goals and aims. It provides evidence of continual improvements that allows the library to stay current and relative in the future. The framework also helps librarians, who are typically not trained in assessment, find resources to help them assess their areas of responsibility, and it promotes a culture of assessment where all library employees are focused on finding data to support decisions and assist in strategic planning. It also serves as a means to determine if the changes made in the library were just different or better.

\section{References}

Applegate, R. (2009). Designing comprehensive assessment plans: The big picture leads to the little picture. [Paper presentation]. ACRL 14th National Conference, Seattle, WA.

Association of College and Research Libraries. (2010). Value of academic libraries: A comprehensive research review and report. Report by Megan Oakleaf. Chicago, IL: Association of College and Research Libraries.

Avery, B. (2015). Assessment in the library. Christian Librarian, 69, 42-46.

Baggett, K., Connell, V., \& Thome, A. (2018). Frame by frame: Using the ACRL framework for information literacy to create a library assessment plan. College \& Research Libraries News, 79(4), 186-200. https://doi.org/10.5860/crln.79.4.186

Cox, A. M., Pinfield, S., \& Rutter, S. (2019). Extending McKinsey's 7S model to understand strategic alignment in academic libraries. Library Management, 40(5), 313-326. https://doi.org/ 10.1108/LM-06-2018-0052

Dunya, B. A., \& De Groote, S. (2017). Review essay: The documentation of library assessment planning process, lessons learned and suggestions. Partnership: The Canadian Journal of Library and Information Practice and Research, 12(1), 1-7. https://doi.org/10.21083/partnership.v12i1.4006

Hockenberry, B., \& Little, M. (2013). How we came to dread Fridays: Developing an academic library assessment plan two hours at time. College \& Undergraduate Libraries, 20(3-4), 277-297. https://doi.org/10.1080/10691316.2013.829379

Lakos, A. (2007). Evidence-based library management: The leadership challenge. Portal: Libraries and the Academy, 7(4), 431-450. https://doi.org/10.1353/pla.2007.0049

Lindauer, B. G. (1998). Defining and measuring the library's impact on campus-wide outcomes. College \& Research Libraries, 59(6), 546-570. https://doi.org/10.5860/crl.59.6.546

Matthews, J. R. (2007). Library assessment in higher education. Libraries Unlimited.

Oakleaf, M. (2012). Academic library value: The impact starter kit. Dellas Graphics.

Ranganathan, S. R. (1931). The five laws of library science. Edward Goldston.

Strategic Directions. (2019). BYU Library Strategic Directions. https://lib.byu.edu/about/strategicdirections/.

Tatarka, A., Chapa, K., Li, X., \& Rutner, J. (2010). Library assessment plans: Four case studies. Performance Measurement and Metrics, 11(2), 199-210. https://doi.org/10.1108/ 14678041011064106

Zaugg, H., \& Child, C. (2016). Collaborating with nonlibrary faculty for assessment and improved instruction. Journal of Library Administration, 56(7), 823-844. https://doi.org/10.1080/ 01930826.2015.1124704

Zaugg, H., McKeen, Q., Hill, B., \& Black, B. (2017). Conducting and using an academic library inventory. Technical Services Quarterly, 34(1), 1-12. https://doi.org/10.1080/07317131.2017. 1238192 


\section{Appendix A: Example of a library impact map}

\begin{tabular}{|c|c|c|c|c|c|c|c|c|c|c|c|c|c|c|c|}
\hline & AUL & \multicolumn{14}{|c|}{ Public Services - MH } \\
\hline & Department Head & $\begin{array}{l}\mathrm{C} \\
\mathrm{R}\end{array}$ & $\mathrm{PZ}$ & $\begin{array}{l}\mathrm{R} \\
\mathrm{W}\end{array}$ & & & & & $\begin{array}{l}\mathrm{M} \\
\mathrm{W}\end{array}$ & & & & & & \\
\hline 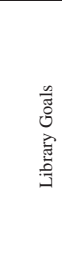 & Library Impact Map & 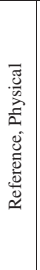 & 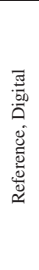 & 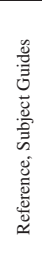 & 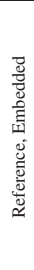 & 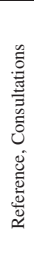 & 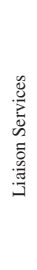 & 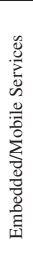 & 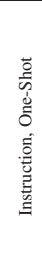 & 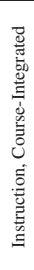 & 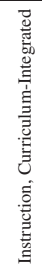 & 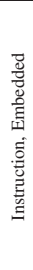 & 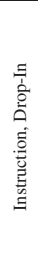 & 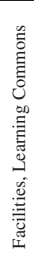 & 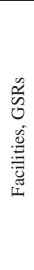 \\
\hline DCFL & Faculty Teaching & $\mathrm{Y}$ & $\mathrm{Y}$ & $\mathrm{Y}$ & $\mathrm{Y}$ & $\mathrm{Y}$ & $\mathrm{Y}$ & $\begin{array}{l}\mathrm{C} \\
\mathrm{B}\end{array}$ & $\mathrm{Y}$ & $\mathrm{Y}$ & $\mathrm{Y}$ & $\begin{array}{l}\mathrm{C} \\
\mathrm{B}\end{array}$ & $\mathrm{Y}$ & $\mathrm{Y}$ & $\begin{array}{l}\mathrm{C} \\
\mathrm{B}\end{array}$ \\
\hline DCFL & Faculty Innovation, Entrepreneurship & $\begin{array}{l}\mathrm{C} \\
\mathrm{B}\end{array}$ & $\begin{array}{l}\mathrm{C} \\
\mathrm{B}\end{array}$ & $\mathrm{CB}$ & $\begin{array}{l}\mathrm{C} \\
\mathrm{B}\end{array}$ & $\begin{array}{l}\mathrm{C} \\
\mathrm{B}\end{array}$ & $\mathrm{Y}$ & $\mathrm{Y}$ & $\mathrm{CB}$ & $\mathrm{N}$ & $\mathrm{N}$ & $\mathrm{N}$ & $\mathrm{N}$ & $\mathrm{N}$ & $\mathrm{N}$ \\
\hline DCFL & Institutional Brand & $\mathrm{N}$ & $\mathrm{N}$ & $\mathrm{N}$ & $\mathrm{N}$ & $\mathrm{N}$ & $\begin{array}{l}\mathrm{C} \\
\mathrm{B}\end{array}$ & $\begin{array}{l}\mathrm{C} \\
\mathrm{B}\end{array}$ & $\mathrm{N}$ & $\mathrm{N}$ & $\mathrm{N}$ & $\mathrm{N}$ & $\mathrm{N}$ & $\mathrm{N}$ & $\mathrm{N}$ \\
\hline DCFL & Institutional Development, Funding, Endowments & $\mathrm{N}$ & $\mathrm{N}$ & $\mathrm{N}$ & $\mathrm{N}$ & $\mathrm{N}$ & $\mathrm{Y}$ & $\mathrm{Y}$ & $\mathrm{N}$ & $\mathrm{N}$ & $\mathrm{N}$ & $\mathrm{N}$ & $\mathrm{N}$ & $\begin{array}{l}\mathrm{C} \\
\mathrm{B}\end{array}$ & $\begin{array}{l}\mathrm{C} \\
\mathrm{B}\end{array}$ \\
\hline $\begin{array}{l}\mathrm{DCN} \\
\mathrm{K}\end{array}$ & Faculty Research Productivity & $\mathrm{Y}$ & $\mathrm{Y}$ & $\mathrm{Y}$ & $\mathrm{Y}$ & $\mathrm{Y}$ & $\mathrm{Y}+$ & $\mathrm{Y}$ & $\mathrm{Y}$ & $\mathrm{N}$ & $\mathrm{Y}$ & $\begin{array}{l}\mathrm{C} \\
\mathrm{B}\end{array}$ & $\mathrm{N}$ & $\mathrm{N}$ & $\mathrm{N}$ \\
\hline $\begin{array}{l}\mathrm{DCN} \\
\mathrm{K}\end{array}$ & $\begin{array}{l}\text { Local, Global Engagement, Community-Building, Social } \\
\text { Inclusion }\end{array}$ & $\mathrm{Y}$ & $\mathrm{Y}$ & $\mathrm{Y}$ & $\mathrm{N}$ & $\mathrm{Y}$ & $\begin{array}{l}\mathrm{C} \\
\mathrm{B}\end{array}$ & $\begin{array}{l}\mathrm{C} \\
\mathrm{B}\end{array}$ & $\mathrm{Y}$ & $\mathrm{Y}$ & $\mathrm{Y}$ & $\begin{array}{l}\mathrm{C} \\
\mathrm{B}\end{array}$ & $\mathrm{Y}$ & $\mathrm{N}$ & $\mathrm{N}$ \\
\hline $\begin{array}{l}\mathrm{DCN} \\
\mathrm{K}\end{array}$ & Character Building & $\mathrm{N}$ & $\mathrm{N}$ & $\mathrm{N}$ & $\mathrm{N}$ & $\mathrm{N}$ & $\mathrm{Y}$ & $\begin{array}{l}\mathrm{C} \\
\mathrm{B}\end{array}$ & $\mathrm{Y}$ & $\mathrm{Y}$ & $\mathrm{Y}$ & $\begin{array}{l}\mathrm{C} \\
\mathrm{B}\end{array}$ & $\mathrm{Y}$ & $\mathrm{Y}$ & $\mathrm{Y}$ \\
\hline IRAC & Student GPA, Test Achievement & $\mathrm{Y}$ & $\mathrm{Y}$ & $\mathrm{Y}$ & $\mathrm{Y}$ & $\mathrm{Y}$ & $\mathrm{Y}$ & $\mathrm{Y}$ & $\mathrm{Y}$ & $\mathrm{Y}$ & $\mathrm{Y}+$ & $\begin{array}{l}\mathrm{C} \\
\mathrm{B}\end{array}$ & $\mathrm{Y}$ & $\begin{array}{l}\mathrm{C} \\
\mathrm{B}\end{array}$ & $\mathrm{Y}$ \\
\hline IRAC & Student Learning Outcomes & $\mathrm{Y}$ & $\mathrm{Y}$ & $\mathrm{Y}$ & $\mathrm{Y}$ & $\mathrm{Y}$ & $\mathrm{Y}$ & $\mathrm{Y}$ & $\mathrm{Y}$ & $\mathrm{Y}$ & $\begin{array}{c}\mathrm{Y}+ \\
+\end{array}$ & $\begin{array}{l}\mathrm{C} \\
\mathrm{B}\end{array}$ & $\mathrm{Y}$ & $\mathrm{Y}$ & $\mathrm{Y}$ \\
\hline IRAC & Faculty Recruitment, Tenure, Promotion & $\mathrm{Y}$ & $\mathrm{Y}$ & $\mathrm{Y}$ & $\mathrm{N}$ & $\mathrm{Y}$ & $\mathrm{Y}$ & $\begin{array}{l}\mathrm{C} \\
\mathrm{B}\end{array}$ & $\mathrm{N}$ & $\mathrm{N}$ & $\mathrm{N}$ & $\mathrm{N}$ & $\mathrm{N}$ & $\begin{array}{l}\mathrm{C} \\
\mathrm{B}\end{array}$ & $\mathrm{N}$ \\
\hline IRAC & Faculty Service & $\mathrm{N}$ & $\mathrm{N}$ & $\mathrm{N}$ & $\mathrm{N}$ & $\mathrm{N}$ & $\mathrm{Y}$ & $\begin{array}{l}\mathrm{C} \\
\mathrm{B}\end{array}$ & $\mathrm{N}$ & $\mathrm{N}$ & $\mathrm{N}$ & $\mathrm{N}$ & $\mathrm{N}$ & $\mathrm{N}$ & $\mathrm{N}$ \\
\hline
\end{tabular}

The Library Impact Map was developed by Megan Oakleaf (2012) and modified for use in the BYU Library. In the two left columns are the university areas of focus and the library goals associated with them. The top three rows are the library division, person responsible for the service and the library service. The intersection of university areas of focus and library services indicates the degree to which data is collected. 


\section{Appendix C: Example of previous library assessments}

\begin{tabular}{|c|c|c|c|c|c|c|c|c|c|c|c|c|c|c|c|c|c|c|c|c|c|c|c|c|c|c|}
\hline & \multicolumn{3}{|c|}{ AS } & \multicolumn{4}{|c|}{ LAO } & \multicolumn{6}{|c|}{ Collection Services } & \multicolumn{6}{|c|}{ Research \& Learning } & \multicolumn{4}{|c|}{ Metadata \& IT } & \multirow[b]{2}{*}{ 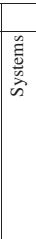 } & \multirow[b]{2}{*}{ 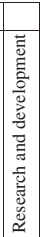 } & \multirow[b]{2}{*}{ 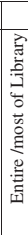 } \\
\hline Assessments & 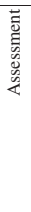 & 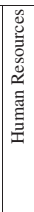 & 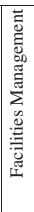 & 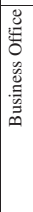 & 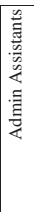 & 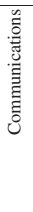 & 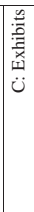 & 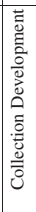 & 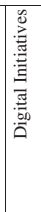 & 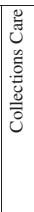 & 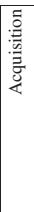 & 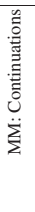 & 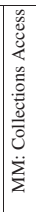 & 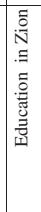 & 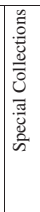 & 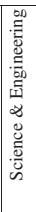 & 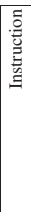 & 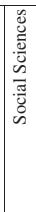 & 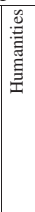 & 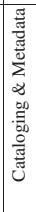 & 苛 & 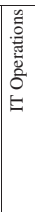 & 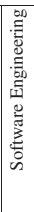 & & & \\
\hline \multicolumn{27}{|c|}{$\begin{array}{l}\text { Inspiring Learning: Recognizing and acting upon opportunities that allow students to have the best experiential learning in their scholarship or as library } \\
\text { employees. }\end{array}$} \\
\hline Undergrad Personas (2014) & & & & & & & & & & & & & & & & & & & & & & & & & & * \\
\hline Grad \& Faculty Personas (2014) & & & & & & & & & & & & & & & & & & & & & & & & & & * \\
\hline LibQUAL+@ Report (2015) & & & & & & & & & & & & & & & & & & & & & & & & & & * \\
\hline \\
\hline \multicolumn{27}{|l|}{$\begin{array}{r}\text { Library Instruction \& ELL } \\
\text { Students (2015) }\end{array}$} \\
\hline \multicolumn{27}{|l|}{$\begin{array}{r}\text { Creativity, Innovation, \& Design } \\
\text { Studio (2015) }\end{array}$} \\
\hline EIZ Christmas in Nauvoo (2016) & & & & & & & & & & & & & & & * & & & & & & & & & & & \\
\hline EIZ Long-Term Displays (2017) & & & & & & & & & & & & & & * & & & & & & & & & & & & \\
\hline \multicolumn{27}{|l|}{\begin{tabular}{r|r} 
HEDS Research Practices Survey \\
$(2018)$
\end{tabular}} \\
\hline \multicolumn{27}{|c|}{$\begin{array}{l}\text { Access: Improving discoverability of and access to resources—especially those unique to BYU—in order to support scholarship and to maximize our } \\
\text { investment in acquiring and preserving this material. }\end{array}$} \\
\hline $\begin{array}{r}\begin{array}{r}\text { Library Orientation \& Tour } \\
(2014)\end{array} \\
\end{array}$ & & & & & & & & & & & & & & & & & * & & & & & & & & & \\
\hline $\begin{array}{r}\text { Reference Activity Summary } \\
\text { (2014) }\end{array}$ & & & & & & & & & & & & & * & & & & & & & & & & & & & \\
\hline Undergrad Personas (2014) & & & & & & & & & & & & & & & & & & & & & & & & & & * \\
\hline Grad \& Faculty Personas (2014) & & & & & & & & & & & & & & & & & & & & & & & & & & * \\
\hline
\end{tabular}

Completed Assessments with date of completion are in the left column. The top two rows are the division and department or unit within the division. Periodic rows (e.g. Inspired Learning) indicate library goals. Intersection is completed assessments. 